\title{
Salvage esophagectomy after high-dose chemoradiotherapy for esophageal squamous cell carcinoma
}

Yuji Tachimori, MD, Norio Kanamori, MD, Norihisa Uemura, MD, Norikazu Hokamura, MD, Hiroyasu Igaki, MD, and Hoichi Kato, MD

Objective: Chemoradiotherapy is a popular definitive therapy for esophageal carcinoma among many patients and oncologists. Although the complete response rates are high and short-term survival is favorable after chemoradiotherapy, persistent or recurrent locoregional disease is frequent. Salvage surgery is the sole curative intent treatment option for this course of the disease. The present study evaluates the safety and value of salvage esophagectomy for locoregional failure after high-dose definitive chemoradiotherapy for esophageal squamous cell carcinoma.

Methods: We reviewed 59 consecutive patients with thoracic esophageal squamous cell carcinoma who underwent salvage esophagectomy after definitive chemoradiotherapy. All patients received more than 60 Gy of radiation plus concurrent chemotherapy for curative intent. The data were compared with those of patients who received esophagectomy without preoperative therapy.

Results: Postoperative morbidity and mortality rates were increased among patients who underwent salvage esophagectomy compared with those who underwent esophagectomy without preoperative therapy (mean hospital stay, 38 vs 33 days; anastomotic leak rates, $31 \%$ vs $25 \%$; respiratory complication rates, $31 \%$ vs $20 \%$; reintubation within 1 week, $2 \%$ vs $2 \%$; hospital mortality rates, $8 \%$ vs $2 \%$ ). Tracheobronchial necrosis and gastric conduit necrosis were highly lethal complications after salvage esophagectomy; 3-year postoperative survivals were $38 \%$ and $58 \%$, respectively.

Conclusion: Patients who underwent salvage esophagectomy after definitive high-dose chemoradiotherapy had increased morbidity and mortality. Nevertheless, this is acceptable in view of the potential long-term survival after salvage esophagectomy. Such treatment should be considered for carefully selected patients at specialized centers.

Surgical resection has been the standard treatment for localized esophageal squamous cell and adenocarcinoma for several decades. Despite many efforts to improve surgical resection, the associated mortality and morbidity rates remain high and the postoperative quality of life is unsatisfactory. Management algorithms for patients with esophageal carcinoma have changed during the last 2 decades. Multidisciplinary approaches have included surgery, radiotherapy, and chemotherapy, alone or in combination. The Radiation Therapy Oncology Group trial (RTOG 85-01), which added chemotherapy to radiotherapy for resectable esophageal carcinoma, has established chemoradiotherapy (CRT) without surgery as one standard for definitive treatment. ${ }^{1,2}$ Many patients and oncologists have accepted the nonsurgical approach with CRT as definitive therapy for esophageal carcinoma. Evaluations of consecutive patients with esoph-

\footnotetext{
From the Esophageal Surgery Division, Departments of Surgery, National Cancer Center Hospital, Chuo-ku, Tokyo, Japan.

This work was supported by a Grant-in Aid for Cancer Research from the Ministry of Health, Labour and Welfare, Japan.

Received for publication Dec 5, 2007; revisions received Feb 23, 2008; accepted for publication May 4, 2008.

Address for reprints: Yuji Tachimori, MD, Department of Surgery, National Cancer Center Hospital, Tsukiji 5-1-1, Chuo-ku, Tokyo 104-0045, Japan (E-mail: ytachimo@ncc.go.jp).

J Thorac Cardiovasc Surg 2009;137:49-54

$0022-5223 / \$ 36.00$

Copyright $\subset 2009$ by The American Association for Thoracic Surgery

doi:10.1016/j.jtcvs.2008.05.016
}

ageal cancer accessed using the National Cancer Database of the American College of Surgeons have shown that radiation combined with chemotherapy is the most frequent treatment strategy for all stages of squamous cell carcinoma in the United States. $^{3}$

Although complete response (CR) rates are high and short-term survival is favorable after definitive CRT, locoregional disease persists or recurs in $40 \%$ to $60 \%$ of patients. ${ }^{4}$ The only curative intent treatment option for locoregional relapse is salvage surgery. ${ }^{5}$ Such patients are at increased risk for esophagectomy because they have been treated with higher doses of radiation and the treatment is usually completed months beforehand. ${ }^{6}$

The present study evaluates the safety and efficacy of salvage esophagectomy for locoregional failure after high-dose definitive CRT for esophageal squamous cell carcinoma. We retrospectively reviewed all patients who underwent esophageal resection between 2000 and 2006 at the National Cancer Center Hospital and selected all patients undergoing salvage esophagectomy after failed definitive CRT $(\mathrm{n}=$ 59). We compared the data with those of patients treated by esophagectomy without preoperative therapy during the same period $(\mathrm{n}=553)$.

\section{MATERIALS AND METHODS}

We reviewed 59 consecutive patients with thoracic esophageal squamous cell carcinoma who underwent salvage esophagectomy after high-dose 


\section{Abbreviations and Acronyms \\ $\mathrm{CR}=$ complete response \\ $\mathrm{CRT}=$ chemoradiotherapy \\ RTOG $=$ Radiation Therapy Oncology Group}

definitive CRT between 2000 and 2006 at the National Cancer Center Hospital, Tokyo. All selected patients had received more than $60 \mathrm{~Gy}$ of external beam radiation as high-dose definitive CRT without planned surgery. The chemotherapeutic regimens for these patients predominantly comprised 5 -fluorouracil and cisplatin concurrently with radiation therapy. These patients included 22 who were initially treated at other hospitals with definitive CRT and who were admitted to the National Cancer Center Hospital after the primary tumor relapsed. We reviewed the other hospital records of these patients to confirm treatment details. Assessments of these patients indicated that 23 had achieved CR after CRT, but disease relapsed later. The remaining 36 patients had not achieved CR and underwent salvage surgery for residual tumors.

The data were compared with those of 553 patients who underwent planned esophagectomy without preoperative therapy during the same period. Long-term outcomes, encompassing overall survival, were obtained from hospital records and the tumor registry. Overall survival was calculated from the day of surgery until death or was censored at the time last known to be alive.

Data were statistically analyzed using the Pearson chi-square test or the Fisher exact test as appropriate. Kaplan-Meier survival curves were estimated with differences based on patient characteristics assessed by the log-rank test to compare the distribution of survival. Survival of the 54 patients who underwent salvage esophagectomy after CRT, excluding perioperative deaths, was examined using univariate and multivariable analyses.

\section{RESULTS}

Table 1 compares the clinical characteristics of patients who underwent salvage esophagectomy after CRT (salvage group) with who did not receive preoperative therapy. The salvage group contained more male patients and less advanced pathologic stages, but age and tumor location did not significantly differ. Of 7 patients with no pathologically residual tumors (pT0) in the resected esophagus, analysis of preoperative endoscopic biopsy revealed that 2 had tumor cells. Another 5 patients had stenosis and ulcers with a thickened wall according to computed tomography examinations suggesting recurrence. All patients with M1 had lymph node metastasis in the neck or celiac area. These patients were indicated for 3-field dissections at the National Cancer Center Hospital. ${ }^{7}$ Patients with distant organ metastasis were not candidates for esophagectomy.

Table 2 compares the surgical procedures and results between the 2 groups. Surgical procedures significantly differed, such as in the extent of lymphadenectomy and reconstruction route. The salvage group tended to have fewer cervical anastomoses ( $75 \%$ vs $96 \%$ ), reflecting a lower proportion of 3 -field lymph node dissections $(41 \%$ vs $91 \%)$. Anastomotic techniques in both groups were similar: Neck anastomosis was performed with the single-layer interrupted hand suture technique, and thoracic
TABLE 1. Clinical characteristics and pathologic factors

\begin{tabular}{|c|c|c|c|}
\hline & $\begin{array}{c}\text { Salvage after } \\
\text { CRT } n=59\end{array}$ & $\begin{array}{l}\text { No preoperative } \\
\text { therapy } n=553\end{array}$ & $P$ value \\
\hline \multicolumn{4}{|l|}{ Gender (No.) } \\
\hline Male & $57(97 \%)$ & $483(87 \%)$ & .0330 \\
\hline Female & $2(3 \%)$ & $70(13 \%)$ & \\
\hline \multicolumn{4}{|l|}{ Age (y) } \\
\hline Median & 63 & 62 & .0821 \\
\hline Range & $34-75$ & $41-83$ & \\
\hline \multicolumn{4}{|l|}{ Location } \\
\hline Upper & $13(22 \%)$ & $88(16 \%)$ & .4839 \\
\hline Middle & $26(44 \%)$ & $261(47 \%)$ & \\
\hline Lower & $20(34 \%)$ & $204(37 \%)$ & \\
\hline \multicolumn{4}{|l|}{$\mathrm{pT}$} \\
\hline pT0 & $7(12 \%)$ & & \\
\hline pT1 & $11(19 \%)$ & $176(32 \%)$ & $<.0001$ \\
\hline pT2 & $5(8 \%)$ & $62(11 \%)$ & \\
\hline pT3 & $30(51 \%)$ & $277(50 \%)$ & \\
\hline pT4 & $6(10 \%)$ & $38(7 \%)$ & \\
\hline \multicolumn{4}{|l|}{$\mathrm{pN}$} \\
\hline $\mathrm{pNO}$ & $38(64 \%)$ & $161(29 \%)$ & $<.0001$ \\
\hline $\mathrm{pN} 1$ & $21(36 \%)$ & $392(71 \%)$ & \\
\hline \multicolumn{4}{|l|}{$\mathrm{pM}$} \\
\hline $\mathrm{pM} 0$ & $52(88 \%)$ & $440(80 \%)$ & .1238 \\
\hline pM1 lym & $7(12 \%)$ & $113(20 \%)$ & \\
\hline \multicolumn{4}{|l|}{ pStage } \\
\hline pStage 0 & $6(10 \%)$ & & .0006 \\
\hline pStage I & $5(9 \%)$ & $93(17 \%)$ & \\
\hline pStage IIA & $20(34 \%)$ & $58(11 \%)$ & \\
\hline pStage IIB & $5(9 \%)$ & $100(18 \%)$ & \\
\hline pStage III & $16(27 \%)$ & $189(34 \%)$ & \\
\hline pStage IVA & $2(3 \%)$ & $19(5 \%)$ & \\
\hline pStage IVB & $5(9 \%)$ & $84(15 \%)$ & \\
\hline
\end{tabular}

CRT, Chemoradiotherapy.

M1 lym had lymph node metastasis in the neck or in the celiac area.

anastomosis was performed with the stapling technique. The rate of noncurative surgery (R1, R2) tended to be more frequent in the salvage group (15\% vs $9 \%)$, but the difference did not reach statistical significance.

Postoperative morbidity and mortality rates were increased in the salvage group compared with those who did not receive preoperative therapy (Table 3 ). The salvage group had more respiratory complications ( $32 \%$ vs $20 \%$ ), including more empyema, mediastinitis, and tracheobronchial necrosis. Tracheobronchial necrosis developed in 4 patients in the salvage group. Tracheobronchial necrosis without anastomotic leak in the neck developed in 2 patients; 1 patient died and 1 patient survived after an omental patch was grafted onto the tracheobronchial fistula. All patients in both groups were extubated in the operating room immediately after surgery. The ratio of those requiring reintubation and ventilation within 1 week after surgery was not increased in the salvage group ( $2 \%$ vs $2 \%)$, whereas rates of anastomotic leakage ( $31 \%$ vs $25 \%$ ) and wound infection 
TABLE 2. Surgical factors

\begin{tabular}{|c|c|c|c|}
\hline & $\begin{array}{c}\text { Salvage after } \\
\text { CRT n }=59\end{array}$ & $\begin{array}{l}\text { No preoperative } \\
\text { therapy } n=553\end{array}$ & $P$ value \\
\hline \multicolumn{4}{|l|}{ Resection approach } \\
\hline Right thoracotomy & $56(95 \%)$ & $539(97 \%)$ & .2740 \\
\hline Left thoracotomy & & $3(1 \%)$ & \\
\hline Transhiatal & $3(5 \%)$ & $11(2 \%)$ & \\
\hline \multicolumn{4}{|l|}{ Lymph node dissection } \\
\hline 3 -field & $24(41 \%)$ & $504(91 \%)$ & $<.0001$ \\
\hline Others & $35(59 \%)$ & $49(9 \%)$ & \\
\hline \multicolumn{4}{|l|}{ Reconstruction conduit } \\
\hline Stomach & $56(95 \%)$ & $506(92 \%)$ & .6931 \\
\hline Colon & $3(5 \%)$ & $42(8 \%)$ & \\
\hline Jejunum & & $2(.4 \%)$ & \\
\hline \multicolumn{4}{|l|}{ Reconstruction route } \\
\hline Anterior & $26(44 \%)$ & $404(73 \%)$ & $<.0001$ \\
\hline Posterior & $31(53 \%)$ & $132(24 \%)$ & \\
\hline Subcutaneous & $2(3 \%)$ & $17(3 \%)$ & \\
\hline \multicolumn{4}{|l|}{ Anastomosis } \\
\hline Cervical & $44(75 \%)$ & $530(96 \%)$ & $<.0001$ \\
\hline Thoracic & $13(22 \%)$ & $17(3 \%)$ & \\
\hline Subcutaneous & $2(3 \%)$ & $6(1 \%)$ & \\
\hline \multicolumn{4}{|l|}{ Curability } \\
\hline R0 & $50(85 \%)$ & $505(91 \%)$ & .1018 \\
\hline $\mathrm{R} 1, \mathrm{R} 2$ & $9(15 \%)$ & $48(9 \%)$ & \\
\hline
\end{tabular}

$C R T$, Chemoradiotherapy.

$(27 \%$ vs $15 \%)$ were significantly increased in the salvage group.

Mean hospital stay (38 vs 33 days) tended to be increased in the salvage group in parallel with increased postoperative morbidity. The hospital mortality rate ( $8 \%$ vs $2 \%$ ) was significantly increased in the salvage group. Table 4 lists the causes of postoperative hospital mortality. A reconstruction via the anterior mediastinum with cervical anastomosis is our standard procedure. One patient died of tracheobron-

TABLE 3. Postoperative morbidity and mortality

\begin{tabular}{lccr}
\hline & $\begin{array}{c}\text { Salvage after } \\
\text { CRT n = 59 }\end{array}$ & $\begin{array}{c}\text { No preoperative } \\
\text { therapy n=553 }\end{array}$ & $\begin{array}{c}\boldsymbol{P} \\
\text { value }\end{array}$ \\
\hline Respiratory complication & $19(32 \%)$ & $113(20 \%)$ & .0452 \\
$\quad$ Pneumonia & $6(10 \%)$ & $46(8 \%)$ & \\
Empyema and & $7(12 \%)$ & $27(5 \%)$ & \\
$\quad$ mediastinitis & $4(7 \%)$ & $1(.2 \%)$ & \\
$\quad$ Tracheobronchial & & & \\
$\quad$ necrosis & $11(19 \%)$ & $127(23 \%)$ & .3396 \\
Recurrent nerve paralysis & $1(2 \%)$ & $10(2 \%)$ & $>.9999$ \\
Ventilation within 1 wk & $2(3 \%)$ & $6(1 \%)$ & .0034 \\
Tracheotomy & $18(31 \%)$ & $138(25 \%)$ & \\
Anastomotic leak & $2(3 \%)$ & $1(.2 \%)$ & .0163 \\
$\quad$ Conduit necrosis & $16(27 \%)$ & $83(15 \%)$ & .1279 \\
Wound infection & $38.3 \pm 35.1$ & $31.2 \pm 33.8$ & .0099 \\
Hospital stay (d) & $5(8 \%)$ & $10(2 \%)$ & \\
Hospital mortality & & $1(.2 \%)$ & \\
Operative mortality & & & \\
\hline
\end{tabular}

$C R T$, Chemoradiotherapy.
TABLE 4. Causes of postoperative hospital mortality

\begin{tabular}{|c|c|c|}
\hline & $\begin{array}{c}\text { Salvage after } \\
\text { CRT } n=59\end{array}$ & $\begin{array}{l}\text { No preoperative } \\
\text { therapy } n=553\end{array}$ \\
\hline Tracheobronchial necrosis & $1(2 \%)$ & \\
\hline $\begin{array}{l}\text { Conduit necrosis and } \\
\text { tracheobronchial necrosis }\end{array}$ & $2(3 \%)$ & $1(0.2 \%)$ \\
\hline Leakage and arterial bleeding & $1(2 \%)$ & $1(0.2 \%)$ \\
\hline $\begin{array}{l}\text { Radiation pneumonitis and } \\
\text { cardiac failure }\end{array}$ & $1(2 \%)$ & \\
\hline Pneumonia & & $3(0.5 \%)$ \\
\hline Leakage and mediastinitis & & $5(0.9 \%)$ \\
\hline
\end{tabular}

chial necrosis without anastomotic leak in the neck. A leak into the posterior mediastinum developed in 1 patient, causing mediastinitis and tracheobronchial necrosis; this patient survived after an omental patch was grafted onto the tracheobronchial fistula. A leak and fatal bleeding from the carotid artery developed in 1 patient. After these events, the reconstruction route was changed to the posterior mediastinum with intrathoracic anastomosis and omental cover onto the tracheobronchus. However, gastric conduit necrosis in the posterior mediastinum caused mediastinitis and tracheobronchial necrosis in 2 patients. After these events, the reconstruction route was returned again to the anterior mediastinum with cervical anastomosis. Neck dissection was canceled in the salvage group, in contrast with the other group who underwent 3-field dissection as a standard procedure. One patient died of interstitial pneumonitis and cardiac failure, which were presumed to have been caused by late toxicity of CRT. Three patients in the salvage group died of respiratory failure and cardiac failure, which were presumed to have been caused by late toxicity of CRT, more than 12 months after salvage surgery.

According to differences in operative morbidity and mortality, overall survival was significantly better in the group who received no preoperative therapy (Figure 1).

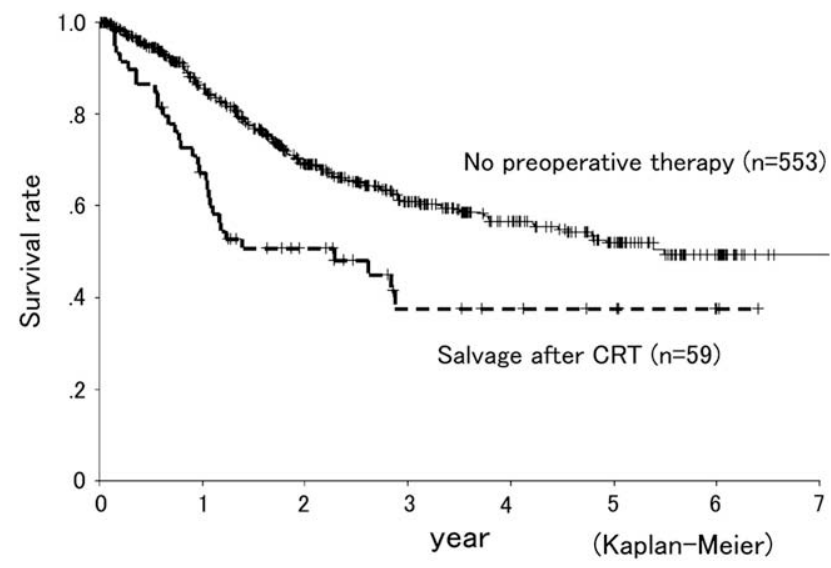

FIGURE 1. Overall survival curves of patients undergoing salvage esophagectomy after definitive CRT $(\mathrm{n}=59)$ or no preoperative therapy $(\mathrm{n}=$ 553). $C R T$, Chemoradiotherapy. 


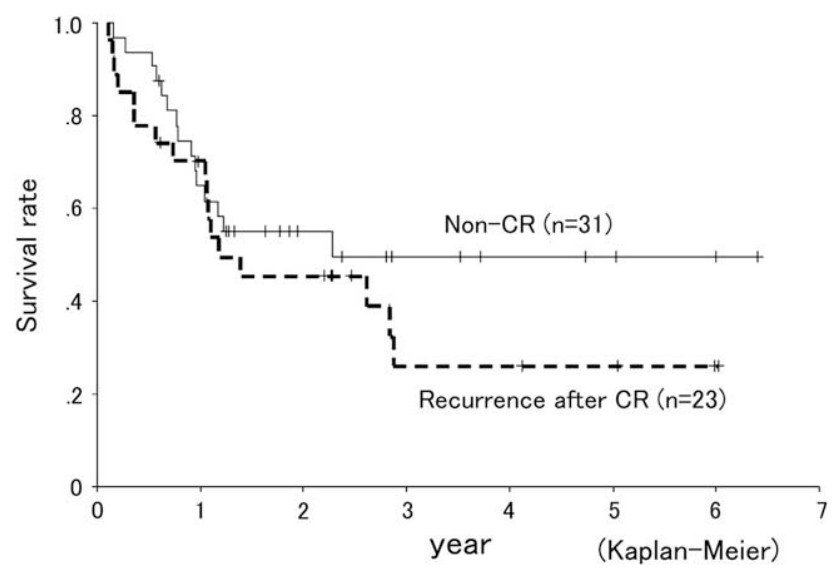

FIGURE 2. Overall survival curves of patients undergoing salvage esophagectomy $(\mathrm{n}=54)$ according to CRT response (excluding perioperative deaths, $\mathrm{n}=5$ ). $C R$, Complete response.

Three-year postoperative survivals were $37.8 \%$ in the salvage group and $60.8 \%$ in the group without preoperative therapy.

We evaluated the factors associated with long-term survival after salvage esophagectomy in the 54 patients who survived the perioperative period. Univariate analysis revealed no associations between increased survival and any of gender, age ( $<60$ or $\geq 60$ years), tumor location, CRT response (recurrence after CR or non-CR; Figure 2), time from CRT to salvage esophagectomy ( $\leq 12$ or $>12$ months), or pathologic $\mathrm{N}$ and $\mathrm{M}$ factors (Table 5). Pathologic $\mathrm{T}$ factor (T1-3 or T4) and R0 resection (R0 or R1-2) were associated with increased survival (Figures 3 and 4). Patients with pathologic T4 and those with noncurative resection (R1-2) closely overlapped. Of 6 patients with pathologic T4 tumors, $\mathrm{R} 0$ resection was performed in only 1 patient via combined resection of the pericardium. Noncurative resection was also completed in 2 patients with peritoneal dissemination and in

TABLE 5. Univariate and multivariate analyses of salvage esophagectomy long-term survival

\begin{tabular}{|c|c|c|c|c|}
\hline \multirow[b]{2}{*}{ Characteristics } & \multicolumn{2}{|c|}{ UnivariateMultivariat } & \multirow[b]{2}{*}{$95 \%$ CI } & \multirow[b]{2}{*}{$P$ value } \\
\hline & $P$ value & HR & & \\
\hline Gender (F/M) & .9288 & 1.574 & $0.168-14.710$ & .6910 \\
\hline Age $(\geq 60 \mathrm{y} /<60 \mathrm{y})$ & .8989 & 3.471 & $0.997-12.084$ & .0505 \\
\hline Location (upper/lower) & .5313 & 1.114 & $0.228-5.436$ & .8942 \\
\hline (middle/lower) & .1773 & 1.884 & $0.578-6.140$ & .2934 \\
\hline $\begin{array}{l}\text { CRT response (recurrence } \\
\text { after } \mathrm{CR} / \text { non-CR) }\end{array}$ & .6371 & 0.786 & $0.212-2.918$ & .7188 \\
\hline $\begin{array}{l}\text { Time from CRT to salvage } \\
\quad(\leq 12 \mathrm{mo} />12 \mathrm{mo})\end{array}$ & .5534 & 1.460 & $0.454-4.698$ & .5256 \\
\hline pT (T1-3/T4) & $<.0001$ & 0.047 & $0.006-0.364$ & .0034 \\
\hline $\mathrm{pN}(\mathrm{N} 0 / \mathrm{N} 1)$ & .1517 & 0.522 & $0.203-1.342$ & .1772 \\
\hline pM (M0/M1-lym) & .0694 & 0.128 & $0.030-0.557$ & .0061 \\
\hline $\mathrm{R}$ (R0/R1-2) & $<.0001$ & 0.421 & $0.070-2.522$ & .3437 \\
\hline
\end{tabular}

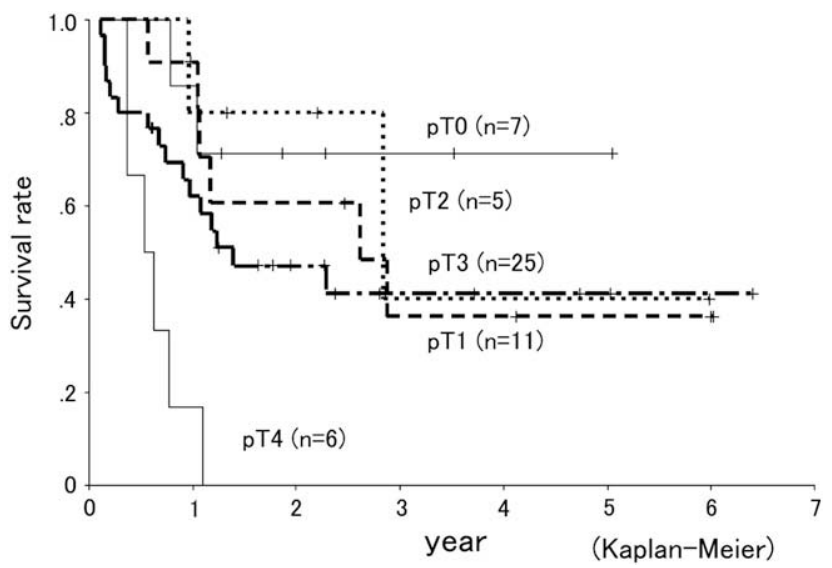

FIGURE 3. Overall survival curves of patients undergoing salvage esophagectomy $(\mathrm{n}=54)$ according to pathologic $\mathrm{T}$ factor (excluding perioperative deaths, $n=5$ ).

1 patient with extended node metastasis. The most significant factor associated with increased survival seemed to be $\mathrm{R} 0$ resection.

\section{DISCUSSION}

In contrast with Western countries, where the rate of adenocarcinoma is increasing, squamous cell carcinoma persists among most Japanese patients with esophageal cancer. ${ }^{89}$ The landmark RTOG 85-01 randomized trials have clearly demonstrated that CRT is a curative approach for squamous cell carcinoma. ${ }^{1,2}$ Medical and radiation oncologists have reported improved survival of patients with esophageal cancer treated by definitive CRT without surgery. ${ }^{10-13}$ Definitive CRT without planned surgery has been offered to patients with potentially resectable esophageal tumors in many Japanese institutions during the past decade. ${ }^{14}$ During the period of this analysis, 480 patients received definitive

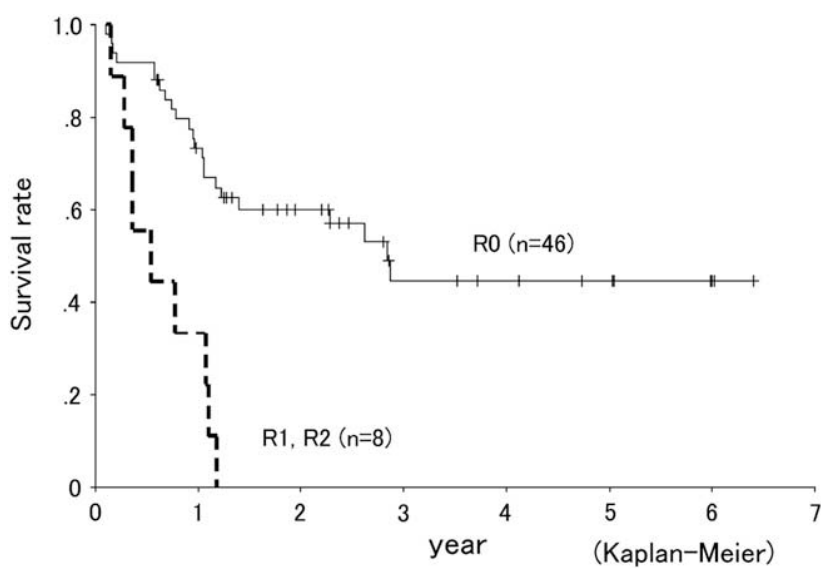

FIGURE 4. Overall survival curves of patients undergoing salvage esophagectomy $(\mathrm{n}=54)$ according to $\mathrm{R}$ classification (excluding perioperative deaths, $\mathrm{n}=5$ ). 
high-dose CRT for stages I to III excluding T4 esophageal squamous cell carcinoma in our institution.

The phase III randomized controlled trial, INT 0123 (RTOG 9405), found no improvement in survival in dose comparisons of high-dose (64.8 Gy) versus standard-dose (50.4 Gy) radiation and the effect on locoregional control did not improve. ${ }^{15}$ Thus, the standard radiation dose for definitive CRT has become 50 to 50.4 Gy in the United States. Definitive CRT has mostly comprised combinations with a conventional radiation dose of more than $60 \mathrm{~Gy}$ in Japan. ${ }^{10-13}$ Clinical trials for definitive CRT at a dose of 50.4 Gy are ongoing. All patients analyzed in the present study were dosed with more than $60 \mathrm{~Gy}$ of external beam radiation as definitive CRT.

Before and during the period of this analysis, 2 consecutive phase III randomized controlled trials at the National Cancer Center Hospital compared the outcomes of postoperative chemotherapy with surgery alone (JCOG9208) ${ }^{16}$ and postoperative chemotherapy with preoperative chemotherapy (JCOG9907) for surgical patients. Less than 10 surgical candidates received the preoperative CRT, and 45 patients received preoperative chemotherapy. Patients who received no preoperative treatment, including surgery alone or surgery with postoperative chemotherapy, comprised the control group for analysis in the present study.

The morbidity and mortality rates of patients who underwent salvage esophagectomy after CRT increased because of the effects of the radiation administered to the mediastinum and the tissues used as conduits. ${ }^{17}$ Higher doses of radiation are associated with increased morbidity, ${ }^{18,19}$ and irradiation of the esophagus and stomach might affect the blood supply, which might contribute to leakage. Gastric conduit necrosis in the posterior mediastinum caused mortal mediastinitis in 2 patients, necessitating surgical modifications to reduce the impact of leaks into the thoracic cavity. The reconstruction route was changed to the anterior mediastinum with cervical anastomosis.

Ischemic tracheobronchial lesions are serious complications of esophagectomy with extensive lymph node dissection, particularly in patients undergoing preoperative CRT. ${ }^{20}$ Four patients in the salvage group developed tracheobronchial necrosis, of which 3 of them died. The remaining patient who received an omental patch graft survived. Protective measures to prevent ischemic tracheobronchial lesions include, in addition to careful dissection around the airway, preservation of the bronchial arteries during resection. ${ }^{21}$ We changed our salvage esophagectomy procedure to preserve the right posterior bronchial artery. Neck dissection was also avoided to preserve the blood supply from the inferior thyroidal artery to the trachea. Although our standard surgery for esophageal cancer is right thoracotomy and 3-field dissection, the extent of lymphadenectomy was reduced in salvage esophagectomy because of high operative risk.
The incidence of acute toxicity of CRT seemed to be substantial. However, long-term or late cardiopulmonary toxicity cannot be ignored in patients who survive after CRT ${ }^{22,23}$ or in those who undergo salvage esophagectomy after CRT. One patient in the salvage group died of interstitial pneumonitis and cardiac failure postoperatively, which were supposedly caused by late toxicity of CRT. In addition, 3 patients died of respiratory failure and cardiac failure more than 12 months after salvage surgery. A strategy to minimize the normal tissue toxicity of CRT should be identified.

We reviewed several factors to identify which subset of patients derived a benefit from salvage esophagectomy. Univariate analysis revealed that T1-3 and R0 were significant factors. The most significant factor associated with longterm survival seemed to be $\mathrm{R} 0$ resection. ${ }^{24,25}$ Fibrosis is usually promoted in radiation fields, and some cancer cells are likely to be left behind in the deep layer of the esophageal wall after radiotherapy. Therefore, to accurately evaluate the $\mathrm{T}$ factor of irradiated patients might be difficult preoperatively, and irradiated tissues are difficult to distinguish from tumors during surgery.

\section{CONCLUSIONS}

Patients who underwent salvage esophagectomy after definitive high-dose CRT had higher morbidity and mortality rates that patients undergoing esophagectomy without preoperative therapy. Nevertheless, this is the only established treatment strategy that offers any chance of long-term survival. This morbidity rate is acceptable in view of the potential for long-term survival after salvage esophagectomy. Patients should be carefully selected for salvage esophagectomy after high-dose CRT at referral centers that specialize in esophageal cancers.

\section{References}

1. Herskovic A, Martz K, al-Sarraf M, Leichman L, Brindle J, Vaitkevicius V, et al. Combined chemotherapy and radiotherapy compared with radiotherapy alone in patients with cancer of the esophagus. $N$ Engl J Med. 1992;326:1593-8.

2. Al-Sarraf M, Martz K, Herskovic A, Leichman L, Brindle JS, Vaitkevicius VK, et al. Progress report of combined chemoradiotherapy versus radiotherapy alone in patients with esophageal cancer: an intergroup study. J Clin Oncol. 1997;15: 277-84. Erratum in: J Clin Oncol. 1997;15:866.

3. Daly JM, Fry WA, Little AG, Winchester DP, McKee RF, Stewart AK, et al. Esophageal cancer: results of an American College of Surgeons Patient Care Evaluation Study. J Am Coll Surg. 2000;190:562-73.

4. Cooper JS, Guo MD, Herskovic A, Macdonald JS, Martenson JA Jr, Al-Sarraf M, et al. Chemoradiotherapy of locally advanced esophageal cancer: long-term follow-up of a prospective randomized trial (RTOG 85-01). Radiation Therapy Oncology Group. JAMA. 1999;281:1623-7.

5. Ajani J, Bekaii-Saab T, D'Amico TA, Fuchs C, Gibson MK, Goldberg M, et al. Esophageal cancer clinical practice guidelines. J Natl Compr Canc Netw. 2006;4: 328-47.

6. Urschel JD, Ashiku S, Thurer R, Sellke FW. Salvage or planned esophagectomy after chemoradiation therapy for locally advanced esophageal cancer-a review. Dis Esophagus. 2003;16:60-5.

7. Tachimori Y, Kato H, Watanabe H. Surgery for thoracic esophageal carcinoma with clinically positive cervical nodes. J Thorac Cardiovasc Surg. 1998;116: 954-9. 
8. The Japanese Esophageal Society. Comprehensive Registry of Esophageal Cancer in Japan 3rd ed. (1998, 1999). Available at: http://esophagus.jp/pdf_files/ CREC_JPN_3rd.pdf. Accessed Feb 23, 2008.

9. Tachimori Y. Esophageal adenocarcinoma in Japanese. J Clin Gastroenterol. 2006;40:S168-9.

10. Ohtsu A, Yoshida S, Boku N, Fujii T, Miyata Y, Hosokawa K, et al. Concurrent chemotherapy and radiation therapy for locally advanced carcinoma of the esophagus. Jpn J Clin Oncol. 1995;25:261-6.

11. Ohtsu A, Boku N, Muro K, Chin K, Muto M, Yoshida S, et al. Definitive chemoradiotherapy for T4 and/or M1 lymph node squamous cell carcinoma of the esophagus. J Clin Oncol. 1999;17:2915-21.

12. Kato H, Udagawa H, Togo A, Ando N, Tanaka O, Shinoda M, et al., Japan Clinical Oncology Group (JCOG). A phase II trial of chemo-radiotherapy in patients with stage I esophageal squamous cell carcinoma: Japan Clinical Oncology Group study (JCOG9708) Abstract No: 1147. Proc Am Soc Clin Oncol. 2003;22:286.

13. Ishida K, Ando N, Yamamoto S, Ide H, Shinoda M. Phase II study of cisplatin and 5-fluorouracil with concurrent radiotherapy in advanced squamous cell carcinoma of the esophagus: a Japan Esophageal Oncology Group (JEOG)/Japan Clinical Oncology Group trial (JCOG9516). Jpn J Clin Oncol. 2004;34:615-9.

14. Hironaka S, Ohtsu A, Boku N, Muto M, Nagashima F, Saito H, et al. Nonrandomized comparison between definitive chemoradiotherapy and radical surgery in patients with $\mathrm{T}(2-3) \mathrm{N}($ any) $\mathrm{M}(0)$ squamous cell carcinoma of the esophagus. Int J Radiat Oncol Biol Phys. 2003;57:425-33.

15. Minsky BD, Pajak TF, Ginsberg RJ, Pisansky TM, Martenson J, Komaki R, et al. INT 0123 (Radiation Therapy Oncology Group 94-05) phase III trial of combined-modality therapy for esophageal cancer: high-dose versus standard-dose radiation therapy. J Clin Oncol. 2002;20:1167-74.

16. Ando N, Iizuka T, Ide H, Ishida K, Shinoda M, Nishimaki T, et al. Japan Clinical Oncology Group. Surgery plus chemotherapy compared with surgery alone for localized squamous cell carcinoma of the thoracic esophagus: a Japan Clinical Oncology Group Study_JCOG9204. J Clin Oncol. 2003;21:4592-6.
17. Chidel MA, Rice TW, Adelstein DJ, Kupelian PA, Suh JH, Becker M. Resectable esophageal carcinoma: local control with neoadjuvant chemotherapy and radiation therapy. Radiology. 1999;213:67-72.

18. Keller SM, Ryan LM, Coia LR, Dang P, Vaught DJ, Diggs C, et al. High dose chemoradiotherapy followed by esophagectomy for adenocarcinoma of the esophagus and gastroesophageal junction: results of a phase II study of the Eastern Cooperative Oncology Group. Cancer. 1998;83:1908-16.

19. Swisher SG, Wynn P, Putnam JB, Mosheim MB, Correa AM, Komaki RR, et al. Salvage esophagectomy for recurrent tumors after definitive chemotherapy and radiotherapy. J Thorac Cardiovasc Surg. 2002;123:175-83.

20. Bartels HE, Stein HJ, Siewert JR. Tracheobronchial lesions following oesophagectomy: prevalence, predisposing factors and outcome. Br J Surg. 1998;85: 403-6.

21. Fujita H, Hawahara H, Yamana H, Shirohazu G, Yoshimura Y, Minami T, et al. Mediastinal lymph node dissection procedure during esophageal cancer operation-carefully considered for preserving respiratory function. Jpn J Surg. 1988;18:31-4

22. Ishikura S, Nihei K, Ohtsu A, Boku N, Hironaka S, Mera K, et al. Long-term toxicity after definitive chemoradiotherapy for squamous cell carcinoma of the thoracic esophagus. J Clin Oncol. 2003;21:2697-702.

23. Carver JR, Shapiro CL, Ng A, Jacobs L, Schwartz C, Virgo KS, et al. ASCO Cancer Survivorship Expert Panel. American Society of Clinical Oncology clinical evidence review on the ongoing care of adult cancer survivors: cardiac and pulmonary late effects. J Clin Oncol. 2007;25:3991-4008.

24. Tomimaru Y, Yano M, Takachi K, Miyashiro I, Ishihara R, Nishiyama K, et al. Factors affecting the prognosis of patients with esophageal cancer undergoing salvage surgery after definitive chemoradiotherapy. J Surg Oncol. 2006; 93:422-8.

25. Oki E, Morita M, Kakeji Y, Ikebe M, Sadanaga N, Egasira A, et al. Salvage esophagectomy after definitive chemoradiotherapy for esophageal cancer. Dis Esophagus. 2007;20:301-4. 